\title{
Sequence analysis of the cupin gene family in Synechocystis PCC6803
}

\section{Article}

Published Version

Dunwell, J. (1998) Sequence analysis of the cupin gene family in Synechocystis PCC6803. Microbial \& comparative genomics, 3 (2). pp. 141-148. ISSN 1090-6592 doi: https://doi.org/10.1089/omi.1.1998.3.141 Available at https://centaur.reading.ac.uk/7956/

It is advisable to refer to the publisher's version if you intend to cite from the work. See Guidance on citing.

To link to this article DOI: http://dx.doi.org/10.1089/omi.1.1998.3.141

Publisher: Mary Ann Liebert, Inc.

All outputs in CentAUR are protected by Intellectual Property Rights law, including copyright law. Copyright and IPR is retained by the creators or other copyright holders. Terms and conditions for use of this material are defined in the End User Agreement.

\section{www.reading.ac.uk/centaur}

\section{CentAUR}

Central Archive at the University of Reading

Reading's research outputs online 


\title{
Sequence Analysis of the Cupin Gene Family in Synechocystis PCC6803
}

\author{
JIM M. DUNWELL
}

\begin{abstract}
The recently described cupin superfamily of proteins includes the germin and germinlike proteins, of which the cereal oxalate oxidase is the best characterized. This superfamily also includes seed storage proteins, in addition to several microbial enzymes and proteins with unknown function. All these proteins are characterized by the conservation of two central motifs, usually containing two or three histidine residues presumed to be involved with metal binding in the catalytic active site. The present study on the coding regions of Synechocystis PCC6803 identifies a previously unknown group of 12 related cupins, each containing the characteristic two-motif signature. This group comprises 11 single-domain proteins, ranging in length from 104 to 289 residues, and includes two phosphomannose isomerases and two epimerases involved in cell wall synthesis, a member of the pirin group of nuclear proteins, a possible transcriptional regulator, and a close relative of a cytochrome c551 from Rhodococcus. Additionally, there is a duplicated, two-domain protein that has close similarity to an oxalate decarboxylase from the fungus Collybia velutipes and that is a putative progenitor of the storage proteins of land plants.
\end{abstract}

\section{INTRODUCTION}

T The cupin superfamily (Dunwell, 1998) of functionally diverse proteins has been designated recently to include the germin and germinlike proteins from plants, their duplicated two-domain relatives, including the seed storage proteins (Bäumlein et al., 1995), and a wide range of other enzymes and binding proteins from microbes, plants, and animals (Dunwell and Gane, 1998). The name cupin (from the Latin cupa, a small barrel or cask) is derived from the tertiary $\beta$-barrel element, which comprises either the central core of these proteins (e.g., oxalate oxidase) or one of a number of discrete domains (e.g., araC transcription factors). Characteristically, the cupin element of these proteins has two histidine-containing motifs, which together with other conserved proline and glycine residues make up the structural framework and the putative metal-binding active site (Gane et al., 1998). The two conserved motifs are separated by a variable region, usually $15-20$ residues in length.

The aim of the present study was to identify and categorize all cupin sequences within a single bacterial genome, namely, that of the unicellular cyanobacterium Synechocystis PCC6803 (Kaneko et al., 1996). This organism serves as the prokaryotic model for studying plantlike oxygenic photosynthesis, and the intention of the present study was to provide a basis from which the proliferation of related plant cupins could

Department of Agricultural Botany, School of Plant Sciences, The University of Reading, Reading RG6 6AS, UK. 


\section{DUNWELL}

be examined systematically. For example, it is estimated that the Arabidopsis genome contains at least 12 germinlike proteins (GLPs) (Dunwell, 1998), in addition to a large number of other related cupins.

\section{METHODS AND RESULTS}

A series of detailed database searches was conducted using the gapped BLAST (Altschul et al., 1997) and BLOCKS (Henikoff and Henikoff, 1991) programs to identify those Synechocystis protein sequences that contain the two conserved histidine-containing motifs described by Dunwell and Gane (1998). These two motifs are part of the $\beta$-strands designated, respectively, $\mathrm{C} / \mathrm{D}$ and $\mathrm{G} / \mathrm{H}$ within the two $\beta$-barrel elements of the bean storage protein phaseolin (Lawrence et al., 1994). A major theme in the present analysis, and the probable reason that this gene family had not been identified previously, is that the region between the two motifs is variable in length, with a minimum distance of 15 residues for many of the bacterial proteins, increasing to around 20 for the germins and GLPs and $>20$ for the storage proteins. The maximum of 64 residues is found in a barley globulin (gi|421978). This variable region, which can tolerate a range of insertions, is equivalent to the $\mathrm{D} / \mathrm{F}$ loop of the $\beta$-barrel structure.

The main result achieved in the present analysis was identification of a total of 12 cupin sequences, of which 11 are single-domain proteins, with one example of a two-domain structure (Fig. 1). Each of these 12 has the characteristic cupin two-motif arrangement, with the consensus of motif 1 being $\mathrm{PG}(\mathrm{X})_{5} \mathrm{HXH}(\mathrm{X})_{4} \mathrm{E}(\mathrm{X})_{7} \mathrm{G}$ and that of motif 2 being $\mathrm{G}(\mathrm{X})_{5} \mathrm{PXG}(\mathrm{X})_{2} \mathrm{H}(\mathrm{X})_{3} \mathrm{~N}$.

The sequences can be subdivided into several classes on the basis of a range of criteria and an analysis of their nearest neighbors according to a BLASTP search (Table 1). In an assessment of potential function, and considering first the 11 single-domain proteins, two of the sequences (gi|1001180, gi|1652486) are thought to be phosphomannose isomerases (PMIs), one (gi|1653678) to be a dTDP-4-dehydrorhamnose 3,5epimerase, and one (gi|1651977) a dTDP-6-deoxy-L-mannose-dehydrogenase. The latter two are very similar in sequence and should probably both be considered as epimerases.

It should be noted that residues $61-129$ of the PMI sequence gi| 1652486 are identical to the sequence encoded by nucleotides 3-208 (with a frameshift correction at position 104) in the upstream region of gi|287460, a sequence including the Synechocystis groES and groEL genes (Lehel et al., 1993). Presumably, this partial PMI coding region was accidentally ligated to the other coding regions during the cloning procedure and then was not identified because of the frameshift introduced by a sequencing error.

Another sequence from which a function can be deduced with some reliability is gi|1652717. This has as its closest neighbor the Escherichia coli sequence gi|1176281, a member of the recently designated group

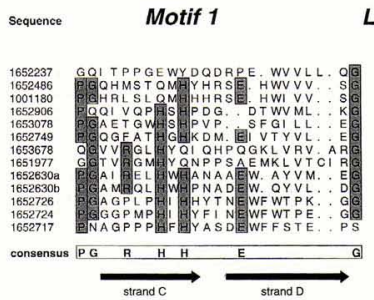

Loop $\quad$ Motif 2

Length

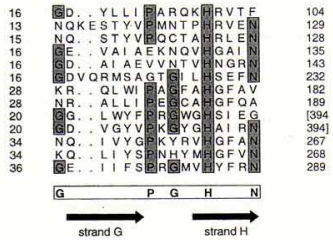

FIG. 1. Sequence alignment of the central core of cupin sequences from Synechocystis PCC6803. Sequences are denoted according to the GenBank gi identifier. The number followed by a and b denote the first and second domain in this two-domain protein. 


\section{SEQUENCE ANALYSIS OF CUPIN GENE FAMILY}

Table 1. ANalysis of Closest Neighbors for Each of the Cupin Sequences from SyneChocystis PCC6803

\begin{tabular}{|c|c|c|c|c|c|c|c|}
\hline \multirow{2}{*}{$\begin{array}{l}\text { Sequence } \\
\text { gi }\end{array}$} & \multicolumn{2}{|c|}{ Closest neighbor } & \multirow{2}{*}{$\begin{array}{c}\text { Length } \\
A A\end{array}$} & \multirow{2}{*}{$\begin{array}{c}\text { Identity } \\
\%\end{array}$} & \multirow{2}{*}{$\begin{array}{c}\text { Similarity } \\
\%\end{array}$} & \multirow{2}{*}{$\begin{array}{c}\text { Gaps } \\
\%\end{array}$} & \multirow[b]{2}{*}{ Function } \\
\hline & $g i$ & Species & & & & & \\
\hline 1652237 & 1657504 & E. coli & 47 & 34 & 55 & - & Transcription regulator \\
\hline 1652486 & 1001180 & Synechocystis & 115 & 61 & 74 & - & PMI \\
\hline 1001180 & 1652486 & Synechocystis & 102 & 63 & 78 & - & PMI \\
\hline 1652906 & 1169942 & M. crystallinum & 95 & 27 & 50 & 9 & GLP \\
\hline 1653078 & 347174 & Rhodococcus & 136 & 30 & 46 & 6 & Cytochrome \\
\hline 1652749 & 1176281 & E. coli & 233 & 48 & 63 & 2 & Pirin \\
\hline 1653678 & 141363 & $S$. enterica & 169 & 65 & 78 & $<1$ & Epimerase \\
\hline 1651977 & 1361427 & S. glaucescens & 179 & 42 & 55 & - & Dehydrogenase \\
\hline 1652726 & 1652724 & Synechocystis & 233 & 48 & 68 & - & ? \\
\hline 1652724 & 1652726 & Synechocystis & 233 & 45 & 65 & - & $?$ \\
\hline 1652717 & 1652724 & Synechocystis & 132 & 26 & 47 & 6 & $?$ \\
\hline 1652630 & 1604990 & C. velutipes & 325 & 38 & 55 & 3 & Oxalate decarboxylate \\
\hline
\end{tabular}

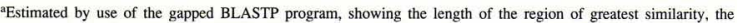
percentages of identical and similar residues, and the percentages of gaps needed to give maximum similarity (TBLASTN was used for the two-domain GI 1652630 sequence, which has a DNA sequence as its neighbor).

of nuclear proteins, the pirins (Fig. 2) (Wendler et al., 1997). Additionally, gil 1653078 is very similar to the Rhodococcus sequence gi|347174, a putative C551 cytochrome, and gi| 1657504 is similar to the $E$. coli transcriptional regulator gi| 1657504 . A lower degree of similarity, with gaps, is found between gi|1652906 and its nearest neighbor, the GLP (gi|1169942) from Mesembryanthemum crystallinum.

Although no function can be assigned yet to the remaining single-domain sequences, the two-domain 394-AA protein (gi|1652630) may be an oxalate decarboxylase, as predicted from its similarity (Fig. 3) to the 447-AA oxalate-degrading enzyme (Mehta and Datta, 1991) from the wood-rotting fungus Collybia velutipes. Its sequence (gi|1604990) has been published recently (Datta et al., 1996).

A detailed quantitative analysis of the cupin sequences shows a number of interesting features. If the singledomain proteins are considered first, in general terms the distance between motifs increases in line with the in-
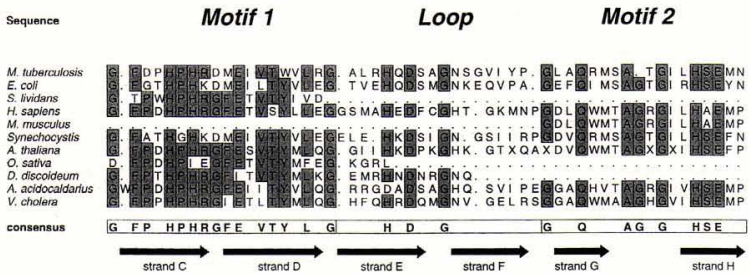

FIG. 2. Sequence alignment of the central core of pirins from a range of microbes, plants, and animals. The details of the sequences used are as follows: Mycobacterium tuberculosis (gi|2213518), Escherichia coli (gi|1789847), Streptomyces lividans (translation of part of the -ve strand of the actinophage phi C31 attachment site gi|48953), Homo sapiens (gi|1907076), Mus musculus (EST gi|1282795), Synechocystis (gi|1652749), Arabidopsis thaliana (EST gi|950773), Oryza sativa (EST gi|1631547), Dictyostelium discoideum (-ve strand 302-3 of upstream sequence of spiA gene, gi 1177288), Alicyclobacillus acidocaldarius (manually edited from -ve strand upstream sequence of amylase gene gi|39300), Vibrio cholerae (sequence included in 538-nucleotide unfinished fragment gnl|TIGR|GVCCX37R). 


\section{DUNWELL}

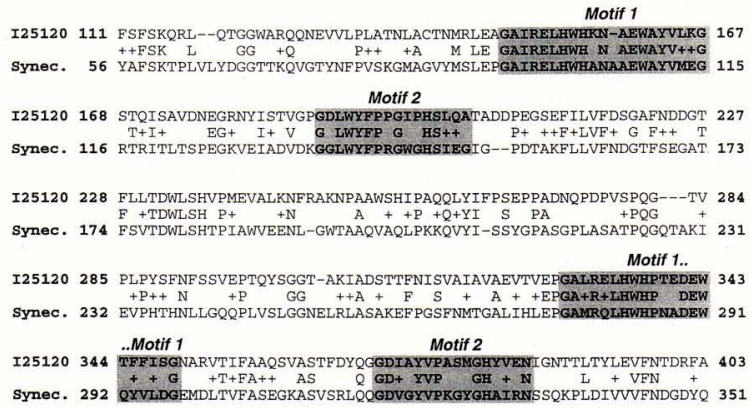

I25120 404 DVSLSQWLALTPPSVVQAHLNLDDETLAEL 433
+ LS WLA P SV+ + E +L

SYnec. 352 SIDLSTWLASNPSSVLGNTEQISPELTKKL 381

FIG. 3. Protein sequences of the two-domain proteins from Synechocystis PCC6803 (gi|1652630) and Collybia velutipes $($ I25120), compared by gapped BLASTP. Score $=210$ bits $(558)$, expect $=1$ e-53, identities $=123 / 330(37 \%)$, positives $(+)=179 / 330(53 \%)$, gaps $=11 / 330(3 \%)$. The shaded boxes denote motifs 1 and 2 within each domain.

crease in overall size of the protein (Fig. 1), from a minimum of 13 residues in the 129-AA gi|1652486 to 36 residues in the 289-AA gi|1652717. The one notable exception to this trend is the 232-AA gi| 1652749 , which has a 16-residue intermotif loop. As reported, the two-domain sequence is related to a fungal decarboxylase. Both have 20 residues between motifs, a spacing characteristic of many of the GLPs from higher plants.

\section{DISCUSSION}

Before the present study, only four of the Synechocystis sequences had been identified as cupins (Dunwell and Gane, 1998). Three of these were single-domain proteins, namely, the PMI gi|1001180 and its two related sequences, gi|1652906 and gi|1653708. The other was the two-domain protein gi| 1652630 . The total number in this paralogous family is now increased to 12 (Fig. 1 and Table 1), although not all of these proteins fulfil the arbitrary definition used in the recent analysis of the E. coli genome (Blattner et al., 1997). These authors used the term to include all those ORFs that share at least $30 \%$ sequence identity over more than $60 \%$ of their lengths. However, it is probably not appropriate to apply this strict criterion to the present group of 12 sequences, which vary in length from 104 to 394 AAs and in which the two most conserved motifs are separated by a nonconserved region of variable length.

Four of the proteins identified in the present study have a possible functional connection, in that they are concerned with cell wall synthesis. The best known are the PMIs (EC 5.3.1.8), enzymes that catalyze the interconversion of mannose-6-phosphate and fructose-6-phosphate. Although they are considered to be zinccontaining metalloproteins, an Fe(III)-hydroxyphenylalanine site has been identified recently in the PMI from Candida albicans when expressed in E. coli (Proudfoot et al., 1996; Smith et al., 1997). On the basis of sequence comparison, PMIs have been divided into three classes (Proudfoot et al., 1994), within which 


\section{SEQUENCE ANALYSIS OF CUPIN GENE FAMILY}

the class II enzymes (those described here) are involved in a variety of pathways, including capsular polysaccharide biosynthesis and D-mannose metabolism. Interestingly, in Synechocystis there seems to be no example of the bifunctional GDP-mannose pyrophosphorylase/PMI enzyme (the PMI domain of about 130 AAs is located at the C-terminus of the protein) found in some Archaea (e.g., the 448-AA gi|2649495 from Archaeoglobus fulgidus) and many eubacteria (e.g., the 428-AA gi|1230580 from Vibrio cholerae and the 470-AA gi|2313118 from Helicobacter pylori) and thought to be involved, for example, in the polymerization of alginate, a viscous mucoid exopolysaccharide. Instead, the two functions in Synechocystis, as in Methanococcus jannaschii (J.M. Dunwell, unpublished observations), are carried out by two separate enzymes, the phosphorylase function by the $367-\mathrm{AA}$ gi 1653346 and the isomerase function by the two PMIs (approximately $128 \mathrm{AA}$ ), gi|1001180 and gi| 1652486 , identified previously. Other bacteria, such as E. coli, contain a family of related enzymes, including PMIs (e.g., the 152-AA gi|147164), as well as several bifunctional enzymes (e.g., the 471-AA gi|585853, the 478-AA gi|1155018, and the 483-AA gi|1584629).

Enzymes, such as the dTDP-4-dehydrorhamnose 3,5-epimerase (gi|1653678) identified here, are involved in the synthesis of bacterial exopolysaccharides. These enzymes include the ExpA8 protein recently shown to be involved in the synthesis of galactoglucan (exopolysaccharide II) in Rhizobium melioti (Becker et al., 1997) and the TDP-deoxyglucose epimerase (L33181) that is part of the biosynthetic pathway for ascarylose, a lipopolysaccharide component in Yersinia pseudotuberculosis (Thorson et al., 1994). The related dTDP-6-deoxy-L-mannose-dehydrogenase (gi|1651977), identified in this study as a cupin, is also involved in cell wall synthesis.

In contrast to the presumed function in cell wall synthesis assigned to the previous four sequences considered, the identity of sequence gi| 1652749 seems to be as the nuclear protein pirin, one of a highly conserved group of proteins (Fig. 2) thought to interact with the nuclear factor I/CCAAT box transcription factor (NFI/CTF1) (Wendler et al., 1997). Of the other sequences, gi|1652237 has the transcriptional regulator gi|1657504 from E. coli as its closest neighbor, and gi|1653078 is similar to gi|347174, a cytochrome C551 gene from Rhodococcus.

Unfortunately, no function can be assigned to any of the other single-domain cupins listed in Figure 1, although it is hoped that as this superfamily is analyzed in more detail, the subgroups will be identified systematically by their homology to proteins of known function - a process that enabled the oxalate oxidase identity of the wheat gf 2.8 germin to be established (Lane et al., 1993).

The detailed analysis summarized in Figure 1 confirmed that all the cupin sequences found in Synechosystis contain the characteristic two-motif structure, with the intermotif distance varying in length from 13 (a uniquely short spacing for this superfamily) to 34 residues. Despite the range of spacing found in this study, it is interesting to note that none of the single-domain cupins in Synechocystis has an intermotif distance of 20 residues, the spacing found in the two-domain sequence gi|1652630. There are a number of possible explanations for this peculiarity. First, it may be that the duplication occurred in a protein with a 16-residue spacing, followed by the insertion of 4 residues in each domain; this seems unlikely. Alternatively, the 20-residue progenitor may have been lost through natural selection or may simply not have been identified in this study. Again it seems unlikely that any other cupin sequences in this genome remain undiscovered. In a further attempt to find close relatives to the two-domain 20-residuc protein from other organisms, the 57-AA sequence spanning the two motifs of domain 1 was used as a probe in a BLASTP search. This revealed an Arabidopsis GLP (U75207) as the closest neighbor, with the closest nonplant sequence being the hypothetical protein gi|2128971 from the archaeon $M$. jannaschii (37\% identical, $48 \%$ similar over a distance of $51 \mathrm{AAs}$ ). However, this 125 AA protein has only a 16-residue gap. Similarly, use of an equivalent sequence from domain 2 revealed the 113-AA sequence gi|1881251 from Bacillus subtilis as the nearest neighbor (37\% identical, $62 \%$ similar over 51 residues). This sequence also has a 16-AA gap. Therefore, to date, there is no known example of a singledomain, 20-AA gap protein from a prokaryote. This apparent lack of any progenitor 20 protein, allied to the multitude of prokaryotic two-domain proteins with the 20 spacing, suggests that there was only one 20 protocupin, which underwent a duplication to produce gi| 1652630 and its equivalents in other species and left no extant progenitor (or at least none identified to date).

Comparison of the alignment of the two-domain sequences from Synechocystis and C. velutipes (Fig. 3) confirms that they are probably derived from the same progenitor and that the former sequence may be the direct progenitor of the latter. This view is reinforced by analysis not only of the conserved motif regions but also of the intervening intermotif regions. Specifically, there are several identical residues in the two 


\section{DUNWELL}

20-AA intermotif regions of the first domain of each protein (consensus XTXIXXXXXEGXXXIXXVXX) and a different set of identical residues (consensus XXXXTXFAXXXXASXXXXQX) in the intermotif regions of the second domain. This suggests strongly that there was divergence of the two domains of a precursor protein after duplication of a 20 -residue protocupin, followed by further minor divergence during the postduplication phase, leading eventually to the present day sequences.

In terms of both their number and their range of size and the presence of a two-domain sequence, the evidence presented suggests that the spectrum of cupins found in Synechocystis is closer to that of higher plants rather than to that found in more primitive bacteria (to date, only two cupins have been identified in M. jannaschii) (Dunwell, 1997). Presumably, there was a rapid expansion of cupin diversity during the evolution of Synechocystis. This conclusion may be related to the observation that the genome of this organism contains 99 ORFs with similarity to transposases (Kaneko et al., 1996). It was suggested that this high frequency could be linked to frequent rearrangement of the genome during and after establishment of this species. More recently, Cassier-Chauvat et al. (1997) characterized three specific insertion sequences from Synechocystis and suggested, on the basis of homology, that they were spread through horizontal transfer between evolutionarily distinct organisms.

Identification of the prokaryotic two-domain sequence in the present study also complicates the conclusion reached by Bäumlein et al. (1995) that "the extant spherulins and germins might represent a stage of seed globulin gene evolution before [my emphasis] the domain duplication event had occurred."

If the linear structure of these 12 Synechocystis cupin sequences is considered, it can be seen that there is an overall increase in spacing between the motifs, coincident with the increase in length of the proteins (Fig. 1). If it is assumed that the progenitor of these proteins was the smallest and most simple of the protocupins, as the overall sequence grew in length by addition of residues at each end, this must have been accompanied by insertion of residues into the variable region, namely, the E/F loop at the end of the $\beta$-barrel (Gane et al., 1997). This gradual increase in complexity led eventually to addition of $\alpha$-helical regions at each end of the protein, duplication into two long $\alpha+\beta$ domains, and finally to assembly of the protein subunits to give the trimeric quaternary structure found in the abundant storage proteins of land plants (Lawrence et al., 1994) (Table 2). In addition, by the present stage of the evolutionary process, two of the three conserved histidines have been lost in most storage proteins (all three in some examples), and as these residues are implicated as being catalytically active (Gane et al., 1998), it is likely that these multimeric proteins no longer have any enzyme activity (none is known). In this regard, it is also not known if the Synechocystis two-domain protein or any of the more primitive two-domain storage proteins show oxalate decarboxylase activity (cf. I25120).

Duplication of domains, followed by their subsequent divergence during evolution, is known to occur in other proteins, such as the zinc metalloenzyme glyoxylase 1 , which catalyzes the glutathione-dependent inactivation of toxic methylglyoxyl (Cameron et al., 1997). In this example, sequence alignment showed that 13 of 74 residues were identical in domain 1 and 13 of 59 in domain 2 . Such relatively low levels of identity occur presumably because of the small number of residues required to provide the conserved structural elements in such proteins. Undoubtedly, as analysis techniques become more sophisticated, more cases of

Table 2. Characteristics of a Sample of Cupin Proteins from the Evolutionary Sequence from Bacteria to Higher Plants ${ }^{a}$

\begin{tabular}{llccccc}
\hline Name & \multicolumn{1}{c}{ Species } & Length AA & Histidines & Loop AA & Domains & Subunits \\
\hline PMI & Synechocystis & 128 & 3 & 13 & 1 & 1 \\
GLP & A. thaliana & 200 & 3 & 20 & 1 & 1 \\
Oxalate oxidase & T. aestivum & 201 & 3 & 23 & 1 & $? 5$ \\
Oxalate decarboxylate & C. velutipes & 447 & 3 & 20 & 2 & 1 \\
Vicilin & P. vulgaris & 397 & 1 & 27 & 2 & 3 \\
\hline
\end{tabular}

aThe proteins are classified according to their name, species of origin, total length, number of conserved histidine residues in the two motifs, length of the intermotif loop, number of domains, and number of subunits in the mature protein. 


\section{SEQUENCE ANALYSIS OF CUPIN GENE FAMILY}

this type of evolutionary process will be revealed, and the number of basic underlying 3D structures will be found to be restricted (Godzik, 1997).

\section{ACKNOWLEDGMENTS}

I would like to acknowledge the financial support of Zeneca plc and the Biotechnology and Biological Sciences Research Council and the expertise of Paul Gane for preparation of the figures.

\section{REFERENCES}

ALTSCHUL, S.F., MADDEN, T.L., SCHAFFER, A.A., ZHANG, J., ZHANG, Z., MILLER, W., et al. (1997). Gapped BLAST and PSI-BLAST: A new generation of protein database search programmes. Nucleic Acids Res 25 , 3389-3402.

BÄUMLEIN, H., BRAUN, H., KAKHOVSKAYA, I.A., and SHUTOV, A.D. (1995). Seed storage proteins of spermatophytes share a common ancestor with desiccation proteins of fungi. J Mol Evol 41, 1070-1075.

BECKER, A., RUBERG, S., KUSTER, H., ROXLAU, A.A., KELLER, M., IVASHINA, T., et al. (1997). The 32-kilobase $\exp$ gene cluster of Rhizobium melioti directing the biosynthesis of galactoglucan: Genetic organization and properties of the encoded gene products. J Bacteriol 179, 1375-1384.

BLATTNER, F.R., PLUNKETT, G., BLOCH, C.A., PERNA, N.T., BURLAND, V., RILEY, M., et al. (1997). The complete genome sequence of Escherichia coli K-12. Science 277, 1453-1462.

CAMERON, A.D., OLIN, B., RIDDERSTRÖM, M., MANNERVIK, B., and JONES, T.A. (1997). Crystal structure of human glyoxylase 1-Evidence for gene duplication and 3D domain swapping. EMBO J 16, 3386-3395.

CASSIER-CHAUVAT, C., PONCELET, M., and CHAUVAT, F. (1997). Three insertion sequences from the cyanobacterium Synechocystis PCC6803 support the occurrence of horizontal DNA transfer among bacteria. Gene 195, 257-266.

DATTA, A., MEHTA, A., and NATARAJAN, K. (1996). Oxalate Decarboxylase. US Patent 5547870.

DUNWELL, J.M. (1997). Cupins: A new superfamily of functionally diverse proteins that include germins and plant storage proteins. Biotech Genet Eng Rev 15, 1-32.

DUNWELL, J.M., and GANE, P.J. (1997). Microbial relatives of seed storage proteins: Conservation of motifs in a functionally diverse superfamily of enzymes. J Mol Evol 45, 147-154.

GANE, P.J., DUNWELL, J.M., and WARWICKER, J. (1997). Modeling based on the structure of vicilins predicts a histidine cluster in the active site of oxalate oxidase. J Mol Evol 45, 488-493.

GODZIK, A. (1997). Counting and classifying possible protein folds. Tibtech 15, 147-151.

HENIKOFF, S., and HENIKOFF, J.G. (1991). Automated assembly of protein blocks for database searching. Nucleic Acids Res 19, 6565-6572.

KANEKO T., SATO, S., KOTANI, H., TANAKA, A., ASAMIZU, E., NAKAMURA, Y., et al. (1996). Sequence analysis of the genome of the unicellular cyanobacterium Synechocystis sp. strain PCC6803. II. Sequence determination of the entire genome and assignment of potential protein-coding regions. DNA Res 3, 109-136.

LANE, B.G., DUNWELL, J.M., RAY, J., SCHMITT, M.R., and CUMING, A.C. (1993). Germin, a protein marker of early plant development, is an oxalate oxidase. J Biol Chem 268, 12239-12242.

LAWRENCE, M.C., IZARD, T., BEUCHAT, M., BLAGROVE, R.J, and COLMAN, P.M. (1994). Structure of phaseolin at 2.2 A resolution: Implications for a common vicilin/legumin structure and the genetic engineering of seed storage proteins. J Mol Biol 238, 748-776.

LEHEL, C., LOS, D., WADA, H., GYORGYEI, J., HORVATH, L., KOVACS, E., et al. (1993). A second groEL-like gene, organized in a groESL operon is present in the genome of Synechocystis sp. PCC 6803. J Biol Chem 268, $1799-1804$.

MEHTA, A., and DATTA, A. (1991). Oxalate decarboxylase from Collybia velutipes. Purification, characterization and cloning. J Biol Chem 266, 23548-23553.

PROUDFOOT, A.E., GOFFIN, L., PAYTON, M.A., WELLS, T.N., and BERNARD, A.R. (1996). In vivo and in vitro folding of a recombinant metalloenzyme, phosphomannose isomerase. Biochem J 318, 437 442 .

PROUDFOOT, A.E.I., TURCATTI, G., WELLS, T.N.C., PAYTON, M.A., and SMITH, D.J. (1994). Purification, cDNA cloning and heterologous expression of human phosphomannose isomerase. Eur J Biochem 219, 415-423.

SMITH, J.J., THOMSON, A.J., PROUDFOOT, A.E., and WELLS, T.N. (1997). Identification of an Fe(III)-dihy- 
droxyphenylalanine site in recombinant phosphomannose isomerase from Candida albicans. Eur J Biochem 244, 325-333.

THORSON, J.S., LO, S.F., PLOUX, O., HE, X., and LIU, H.W. (1994). Studies on the biosynthesis of 3,6-dideoxyhexoses: Molecular cloning and characterization of the asc (ascarylose) region from Yersinia pseudotuberculosis serogroup VA. J Bacteriol 176, 5483-5493.

WENDLER, W.M.F., KREMMER, E., FOERSTER, R., and WINNACKER, E.L. (1997). Identification of pirin, a novel highly conserved nuclear protein. J Biol Chem 272, 8482-8489.

Address reprint requests to:

Jim M. Dunwell

Department of Agricultural Botany

School of Plant Sciences

The University of Reading

Whiteknights PO Box 221

Reading RG6 6AS 